\title{
Teacher Training Technologies in Poland and Ukraine
}

\author{
O. V. Kuchai* \\ Department of pre-primary and elementary education, Bohdan Khmelnytskiy national university at Cherkasy, Cherkasy, Ukraine \\ *Corresponding author: kuchay@ukr.net
}

Received September 28, 2013; Revised October, 10, 2013; Accepted November 24, 2013

\begin{abstract}
The article presents the humanization and democratization of the educational process of vocational and educational training teachers Ukraine, implementation of new educational technologies, finding the most optimal conceptual approaches to the development of national pedagogy cause growth of scientific and practical interest to study the experience of secondary and higher education, including the Republic of Poland. European requirements for teacher training, the quality of their professional qualifications and competencies, professional development of teachers - is the most pressing issue of training teachers in Europe. Polish scientists actively working on finding optimal ways of improving training of primary school teachers in higher education. The most important industrial and educational and developmental functions performed by primary school teacher in the Ukraine, is a professional and personal self-help that improve the professional competence and pedagogical skills through personal and professional self-development, creating conditions for self-development and self-disclosure by the child selfdevelopment technologies and techniques.
\end{abstract}

Keywords: teacher training, universities, schools, Poland, Ukraine

Cite This Article: O. V. Kuchai, “Teacher Training Technologies in Poland and Ukraine.” American Journal of Educational Research 1, no. 11 (2013): 566-570. doi: 10.12691/education-1-11-19.

\section{Introduction}

One of the main factors of progress in education is the quality of teacher training. The increasing complexity of the tasks and functions of school teachers in accordance with the requirements of all sectors of education reform necessitated increasing demands for its vocational and educational training, contents, methods and means of formation of future teachers' high professional and special erudition.

Nowadays, there is an intensive search for the most appropriate contents and structure of vocational and educational training of teachers in different European countries. Radical changes, which the history education in Ukraine is now experiencing, require the review of the number of issues concerning the role of historical, psychological and pedagogical disciplines in higher education institutions which train future teachers.

\section{Analysis of Research on the Problem}

The reform of education and training of teachers in Poland has been researched by many scientists, among them G. Kviatkovska, C. Kupisyevich, C. Pan, S. Levovitski, K. Deneka, M. Szymanski, J. Rutkoviak and others.

One cannot but mention the results of research work of Ukrainian scientists who are actively engaged in the problem of future teachers training: V. I. Bondar, A. J. Kapskey, O. V. Moroz, O. V. KyrychukO.Ya. Savchenko.
Humanization and democratization of the educational process of teachers training in Ukraine, implementation of new educational technologies, finding the most optimal conceptual approaches to the development of national pedagogy cause growth of scientific and practical interest to study the experience of secondary and higher education , including the Republic of Poland. The need to identify common approaches in the development of the national education system and reform of teacher training in higher educational institutions of Ukraine and Poland [1].

\section{Theoretical Training of a Modern School Teacher in Poland and Ukraine}

In modern society education makes high demands on the teacher. This is due to new societal needs in the world of the early twenty-first century. One of the goals of global informatization of education is to prepare teachers who possess a high level of multimedia technologies, to use the latter in the educational process and education management and actively participate in the process of education informatization.

Analysis of the graduates' activity helped to identify the following conflicts between:

- traditional system of education, which is in deep crisis, and the new conditions of the global introduction of multimedia technology in all spheres of a modern man;

- requirements for pedagogical work which has to be individually creative and too formalized system of teacher training;

- rapid development of science and trends of transition to information society, which is clearly traceable now, 
aggravate the contradictions between the amount of information received by mankind and its assimilation capabilities. There is an urgent need for prospective teachers to master the multimedia technologies;

- inexhaustible didactic possibilities of global information network Internet and the low use of the latter in the training process of future teachers of primary school;

- rapid computerization of education in secondary schools and unreadiness of primary school teachers to use multimedia technology.

Low level of information culture of primary school teachers has led to the fact that the teacher is mostly just a consumer of readymade didactic products, not ready to create his own authors training and educational activities. Understanding the need for large-scale introduction of multimedia technologies in educational process in schools and universities has not yet found a complete application in practice. The use of multimedia technology in teaching is understood by many practitioners as a fragmented use in the study of certain subjects.

\subsection{European Requirements for Teacher Training}

European requirements for teacher training, the quality of their professional qualifications and competencies, professional development of teachers - is the most pressing issue of training teachers in Europe. It is very difficult to create a universal, while effective for different countries, model of modern teacher and identify a set of necessary professional qualifications, skills and competencies, especially in dynamic changes in different spheres of social and cultural life of European society. The discussions on these issues provoked the research aimed at defining a set of professional skills necessary for the effective operation of Polish primary school teachers under the conditions of today's European integration and education reform, specifying conditions of their professional development.

Polish scientists are actively working on finding the most acceptable ways of improving training of primary school teachers in higher education. One of the ways for Polish researchers is the improvement of teacher education in shaping the professional competence of primary school teachers, giving preference to the most efficient implementation concepts and models of training teaching staff in the modern world. Ukraine needs intensive development of the process of informatization of education. For national education it is urgent to introduce the learning process of secondary and higher education new multimedia technologies, which are indispensable for scientific and technological progress. As one can see, training of primary school teachers by means of multimedia technologies is rather a pressing issue. It should be noted that Poland is ahead of Ukraine in many ways as for successful solution to this problem.

In connection with the European orientation of Ukraine in general and access to the European labor market in particular, the level of competitiveness of domestic higher education requires a more demanding attitude towards them, and this, in turn, leads to a deeper analysis of trends in European and global education. Under the provisions of the Bologna Process, the main directions to renovate the education are the quality of education, confidence building between business education, compliance with European labor market mobility, increased social status and professionalism of educators, strengthening their state and public support. Therefore, special attention is paid to the professionalism of primary school educator: his professional knowledge, skills, teaching culture, personal and professional development and self-development.

The most important industrial, educational and developmental functions performed by primary school teacher in Ukraine are a professional and personal selfimprovement that is development of professional competence and pedagogical skills through personal and professional self- improvement; creating conditions for self-development and self-disclosure of the child with the help of self-developing technologies and techniques.

The readiness of future primary school teacher in Ukraine is based on the psychological, pedagogical and subject training, which involves, first of all, formation of personality traits of future teachers.

According to N. Kozakova, an important part of training of primary school teachers is pedagogical practice which aims, on the one hand, at the consolidation and implementation under special circumstances of the subject knowledge acquired by the students, also psychological, pedagogical and methodological knowledge and skills needed for future professional activities at school, on the other hand - at creative development and selfdevelopment of future teachers, forming his professionally significant qualities and commitment to innovative teaching activities [2].

\subsection{Factors of Primary School Teachers' Training}

L. Khomych singled out the factors that will contribute to the improvement of training primary school teachers, namely:

- Socio-economic, which are associated with changes in social consciousness and the emergence of new values in society, that means that most attention is paid to selfdevelopment, self-upbringing and self-education of future specialists;

- Practical, caused by socio-economic changes in our country and the emergence of new types of educational institutions. The latter need a teacher with a holistic view of professional activities. Therefore, future teachers must learn to act independently, learn the process of psychopedagogical training of special abilities and skills of interaction and communication;

- Theoretical factors arising not only from socioeconomic, but also from practical changes in the development of education. In this regard, most of the educational institutions of Ukraine include integrated courses of psychological and educational research into the curriculum, and on this basis they organize the formation of professionally important qualities of future teachers, their professional identity and behavior, as well as contribute to the development of individuality of future primary school teacher [3].

\subsection{Modern Model of Training Future Teachers}

Professional activities of a modern teacher require a number of different capacities, among which the creative 
activity and innovation are of great importance. Modern education aims at changing the current educational practice and bringing it to public use. The transformations, taking place in modern society, change its expectations towards school.

The basis of the modern model of future teachers is the idea that in the European dimension a teacher must be creative, aimed at searching, initiative, active, open to innovation, should be a partner in a dialogue with the student.

Issues of teachers' self-assessment of their attitude towards innovation and creativity were also analyzed in the research. The results show that respondents largely differ by their creativity and ability to creative work. Mainly, the understanding of the phrase "a creative, open to change teacher" by different educators was investigated.

In the Polish scientific literature one can find a description of the phenomenon many-faceted studies of teacher and his profession. The research is being conducted, preferably within pedevtology - science about the teacher. However, the research, its analysis are the key aspects of teacher's work and are only marginally related to the professional activities of teachers at different steps of the educational process, particularly in preschools and elementary schools.

Theoretical training teachers of the modern school provides its successful practice. Practical commitment is evident in the external (subject) skills. These include organizational and communication skills. In their turn, these skills are comprehensive, universal and basically involve formation of a number of other skills, such as classification, mobilization skills, information skills, developing skills, interpretation. Together with the given it is very important to possess different teaching techniques, own the ability to empathy, flexibility and dynamism.

The entire range of theoretical and practical commitment to the profession of the teacher is the basis of his various professional competence that is the system.

Model of contemporary teachers of elementary schools, including teacher professiogram (job description), also includes starting, basic and specific competences. Having noted the range of necessary competences for teachers of the modern school, we emphasize that with subject competency (which is part of the pedagogical skills), teachers should have pragmatic competencies to ensure quality and efficiency of the organization and planning of the educational process according to the peculiarities of child's development. While working with a young child creative competence is particularly important. At the same time, work in an elementary school also requires a broad range of competences in the field of cooperation not only with the pupil, but also with his family, with special institutions of society that is widely understood. In the kindergarten and elementary school a child acquires basic language, subject and generic skills, begin to learn foreign languages and so forth. He knows a lot. Along with him there must be a teacher who is capable to help and explain in any situation, teach a child to act in a certain way, including the use of a computer. Younger pupils do not always know how to build properly the relationships with classmates, teachers, and other environments. His language and system of communication is not formed. In this regard, the teacher must know the principles and conditionality of proper communication techniques, know nonverbal communication, possess a good command of speech culture.

The model structure of the modern school teacher involves together with the basic competencies, needed to the teacher of any specialization, a number of specific competencies that provide quality training and education of children. The list of competencies and skills that characterize teachers, one should point out also tutorial abilities that are especially important in the work with a small child, who grows dependent and often dependent from adult.

European requirements for the training of teachers, the quality of their professional qualifications and competencies, professional development of teachers - are the most urgent issues of teacher training in Europe. It is very difficult to create a universal, while effective for different countries, model of modern teachers and identify a set of necessary professional qualifications, skills and competencies, especially in dynamic changes in different spheres of social and cultural life of European society. These factors, discussions on this issue led to the beginning of the search and identifying a set of professional skills necessary for the effective operation of Polish teachers in today's European integration and education reform, specifying conditions of their professional development.

A modern teacher is showing pupils the experience modern ways of mastering knowledge, teaching methods and use of knowledge and becomes rather an organizer of the learning process than a bearer of knowledge.

Both in Poland and in other European countries and in the world the psychological trend in research of teacher's profession has deep traditions [4]. The first studies on the teacher (XIX and XX centuries), focused on finding the theoretical model of an ideal teacher.

A new dimension of educational functions and tasks is presented by Shempruh J. [5]. Author also includes the care for the cognitive capabilities of pupils, the development of their creative thinking, public patience, critical thinking and learning different ways of behavior in difficult situations. A modern school introduced new pedagogical functions for teachers related to their promotion through the ranks. These include: mentor to novice teachers (teacher - trainee), whose mission is to provide professional assistance to novice teachers; guidance of subject group/ association, the organization of the association and providing consultations; guidance of a group of kindergarteners, organizing some form of developing pedagogical competencies according to the priorities of the school and the like.

\subsection{Task of Teachers Related to the Reform of the Polish Education}

Current tasks assigned to the teacher, related to the reform of the Polish education, imply that:

- education and training should be an integral part of the school;

- such important elements as the transference of information, the development of skills and competencies, upbringing should be proportionally combined in schooling;

- a pupil is in the centre of school work. In this regard, the most important has to be his development, not curricular requirements of individual subjects; 
- the school system, especially at the primary level should have integrative nature, that integrate different areas of knowledge;

- the school system should be homogeneous in nature, which is guaranteed be the state; this task is realized in granting autonomy to the school community: its director, teachers, parents and pupils;

- The school environment should create conditions for efficient cooperation of the teaching staff, ensure the educational conditions of the ideas and principles of developmental education.

\subsection{Features of Teacher Training}

The training of teachers, according to V. Okon' [7], is characterized by the following features:

- implementation of educational work by people with different levels of qualifications (higher education and vocational training). Candidates for the post of teachers often choose this profession by chance without an appropriate system of incentive, the result of failed exams to a different direction. Lack of professional identification is often a barrier to the development of relevant skills and professionalism of a man;

- schools often do not have good scientific and didactic base, professorial staff, relevant program;

- institutions that train primary school teachers often use ineffective methods and means of work, which do not correspond to modern requirements, needs and expectations of pupils. In universities the principle of treating students as subjects of study with their independence, enhancing their intellectual and creative potential of the relationship is often not honored;

- Pedagogy and Psychology are seen as a branch of instrumental knowledge, separately from the cultural and social context.

In this regard, the author emphasizes the need for modification of the existing model of teacher training. V. Okon' thus formulates the directions of proposed changes: making changes in the structure of training teachers, especially the selection of university teachers, appropriate selection of applicants for pedagogic institutions; training future teachers, based on the current corresponding to the appearance of Polish schools and educational reality, changing programs; providing institutions, teachers engaged in teaching with relevant research and experimental schools; collaboration with educational, cultural and other institutions interested in the appropriate level of qualifications of teachers.

\section{Conclusion and Recommendation}

Undoubtedly, the success of the modernization of education both in Poland and in Ukraine is largely dependent on the quality of training of teachers capable of intellectual and personal development of students as the basis for the successful functioning of a person under the conditions of permanent changes. Particular attention should be given to training teachers for the purposes of vocational education as changes in the economy, the progress of scientific and technological revolution, the process of European integration require the higher level of training the highly skilled workers.

One of the areas of training of primary school teachers is forming their technological competencies. In particular, L. Makarenko considers computer literacy as an element of training future elementary school teachers. The research, performed by L. Petukhova, is the first to give the scientifically grounded theoretical and methodological and conceptual bases of formation of technological competencies of primary school teachers in higher education; it introduced into scientific use the term "threesubjective didactics" as a modern model of education, the essence and structure of the phenomenon "technological competence of future teachers of elementary school”. It is shown that the formation of technological competence of future teachers of primary school is effective under the condition of creating the information and communication teaching environment as an equal partner in the educational process. The essential characteristics of information-communication educational environment were found out. A didactic model of definite phenomenon on the material of the course "History of Pedagogics", based on the integration of the traditional information and communication forms and methods of teaching was introduced. The research defined organizational and pedagogical conditions (adaptation of the content of training of primary school teachers in accordance with modern requirements, efficient combination of traditional and computer technology education and promotion of educational activity of students; enhancing motivation and interest of students to acquire knowledge; the formation of professional skills through the development of creative thinking of students; involving them in productive research; the use of hypertext, multimedia and distance learning as a platform of building a modern computer-oriented teacher training system; taking into account the characteristics and aspirations of students focused on individual education programs; systematic and operational control and correction of student learning outcomes), evaluation criteria (amount of knowledge, practical skills, formation of motivation, reflection), components (motivation , semantic, procedural and active, reflexive) technological competencies of primary school teachers and the level of their formation (starter, basic, standardized, reproductive and research, productive) and also varieties of technological competencies (technological - collecting, technological - converting, technological - saving , technological - networking, technological - presenting) [8].

Technological training of primary school teachers in the light of humanistic paradigm is to build humanistic orientation of educational activities. By the humanistic orientation we mean the unity of motivational values of an individual, based on the attitude to a man as to the highest value. Such orientation determines, stimulates all types and forms of relationships of the participants of educational process, the contents of the teacher's activity. Humanistic orientation of future primary school teacher is defined as a professional capacity, which is the basis of developing in children respect for others, responsibility, care, doing good.

The level of readiness of a teacher is revealed in the ability to structure their plan of actions, to guide the activities of students, suitability to apply the methods of 
training and education under certain circumstances, the ability to control the behavior and activity of students to find and contact the right tone in relations with them, the ability to make decisions instantly and find the most effective means of pedagogical influence on them.

\section{References}

[1] Pasichnyk, V.R, The training system of history teachers in Poland (80-90-ies of XX century), manuscript dissertation for the degree of candidate of pedagogical sciences: specialty 13.00.04 - Theory and Methods of Professional Education, Kyiv, 2001, 20.

[2] O.V. Handabura, Features of vocational and educational training of primary school teachers. [Online]. Available: http://archive.nbuv.gov.ua/portal/soc_gum/pfto/2010_9/files/pd91 0_51.pdf.

[3] Khomych, L.O, Vocational and educational training of primary school teacher, Magistr-S, Kyiv, 1998, 199.

[4] Pevtsova, E. A., "Teacher Professionalism: The Edge of Excellence: Student-oriented educational concept requires the teacher self-reflection means activity," Uchitel', 6, 78-80, 2000.

[5] Szempruch, J, Teacher in changing schools. Operation and professional development, Foshe, Rzeshuw, 2001, 194.

[6] Kwiecinski, Z., Sliwerski, B, Pedagogics. Tom II, PWN, Warszawa, 2003, 98-122.

[7] Okon, W, The thing o teacher education, WsiP, Warszawa, 1991, 242.

[8] Telychko, N.V, Analysis of training areas of primary school teachers. [Online]. Available:

http://archive.nbuv.gov.ua/portal/soc_gum/znpnapv_ppn/2012_63/ 12tnvyps.pdf. 